\title{
Towards Digitally Archiving the 'Sharinda' A case study of the video documentary mode for showcasing multidimensional cultural traces
}

\author{
Ashes Gupta \\ Professor, Dept. of English, Tripura University, (A Central University), Suryamaninagar, \\ Agartala, Tripura, India. Orcid.org/oooo-0002-5881-8468. \\ Email: ashesgupta@tripurauniv.in
}

\begin{abstract}
It all began with the shooting of a documentary on the ethnic musical instruments of Tripura (specifically a video snippet on the 'sharinda'). The idea was to document and hence to preserve them from oblivion. And keeping in mind the simple logic that essence of any musical instrument is the musicality of tune and rhythm that it offers, audio-visual mode was the obvious choice for documentation, since after all a typographical text cannot reproduce sound. The very technicality of the video documentary necessitated a holistic and comprehensive understanding of the way in which the making, music, instrumentalist trinary in focus has to be shot and documented against the backdrop of the geographical features of the land and landscape of origin, with the audio track reproducing to precision the nuances of the sound reinforced by the voice-over of the poetic texts that spoke about both the instrument and the landscape.

The live cultural circuit (to borrow and modify Louise Rosenblatt's proposition in 'Literature as Exploration '(1938) that evolves out of this intellectual osmosis has been spoken of by several theoreticians, Henry Kreisel and Ashis Nandy being the most prominent. Henry Kreisel is of the view that all discussion to the literature produced in the Canadian West or the Canadian Prairie "must of necessity begin with the impact of the landscape upon the mind" (173). What is true of the Canadian Prairie literature is universally true for all literatures across the world and also for all cultural texts in their all-inclusive textuality including music and musical instruments. In the process of shooting and editing it was perceived that every instrument such as the sharinda is inextricably intertwined with the landscape and its physical details, often replicating the natural ecological sounds, utilizing ecofriendly material and reinforcing Ashis Nandy's proposition: "Ours probably is the age of homopsychogeographicus." (Nandy 1999 305; italics mine.)

This could be extended to the hypothesis that every cultural trace and space including literature and music are ultimately attempts at initiating a cartography of the mind, whose documentation should invariably facilitate an understanding of the 'homopsychogeographicus' of the self. This paper attempts to deal with the inevitable intellectual osmosis that facilitates interaction between geography (in the sense of landscape features) and the human psyche (homopsychogeographicus) to produce cultural products including ethnic musical instruments, literature etc. and the way in which they fuse with each other to make a documentary possible.
\end{abstract}

Keywords: Sharinda, documentary, North East

The close link between literature and geography as well as landscape and the human psyche has always intrigued me, probably since I belong to the third generation of a refugee family that had migrated from Bangladesh (erstwhile East Pakistan and even before that East Bengal) to Tripura

(c) AesthetixMS 2016. This Open Access article is published under a Creative Commons Attribution Non-Commercial 4.0 International License (http://creativecommons.org/licenses/by-nc/4.o/), which permits non-commercial re-use, distribution, and reproduction in any medium, provided the original work is properly cited. For citation use the DOI. For commercial re-use, please contact editor@chitrolekha.com 
in India during partition. Nurtured on regular nightly diets of stories and anecdotes by my grandmother about the land and landscape lost and left behind, I grew up to believe that Tripura was only my land of refuge -my 'basha', whereas for me and my family the real homeland lay on the other side of the border-my 'adibari". Such was the emotional intensity and performative excellence of those narrations that I could almost visualize that lush green, undulating land washed by innumerable meandering rivers- a blend of geographical and emotional codes. Now when I look back, I feel that this was my first perception of that indelible link between landscape and the human psyche, geography and narrative. The alluring geographical details of that absent and lost land I have never seen nor ever been to have always haunted me. This strange emotional affinity to the geography of the lost land only remembered in oral narratives oriented my homopsychographicus ${ }^{3}$, to quote Ashis Nandy, to such an extent that, as discussed subsequently in this paper, I ran the risk of falling a prey to the wrong ideology of standardization, legitimizing and naturalizing that the sharind $\mathrm{a}^{4}$ is monotonous while the sarengi ${ }^{5}$ is melodious. As a student of literature and culture I have constantly felt the need to explore this blurring of disciplinary margins that facilitates what I have termed in this paper as 'intellectual osmosis'. The idea is not just the vindication of this sipping-in operative at interdisciplinary margins, but also a perception and then communication of this phenomenon across mediums generating meaning. Infact, this interdisciplinary proximity appeared even more intense when such issues demanded documentation of the myriad connotations of the disciplines involved as well as the limitations of the medium of typographical text.

The limitations of a typographical text such as a research paper as a medium of documentation and communication and the resultant problematic vis-à-vis the relevance of the video documentary mode as a more viable medium of digital archiving, documentation and communication facilitating 'intellectual osmosis' was even more acutely felt while shooting a video documentary snippet on sharinda an ethnic musical instrument of Tripura. The idea was to document and hence to preserve such instruments from oblivion. And keeping in mind the simple logic that essence of any musical instrument is the musicality of tune and rhythm that it offers, audio-visual mode was the obvious choice for documentation, since after all a typographical text cannot reproduce sound. But the topic in focus did not limit itself to such simplistic explications alone. The ethnic musical instrument sharinda in itself provided a space for the confluence of oral folktale, geographical features of the landscape that serves as the backdrop and reinforce notions of its cultural specificity, the making, the music and the instrumentalist as well as literary traces existent in the form of Kokbarak ${ }^{6}$ poems. It was curious to note that the very technicality of video documentary making necessitated a holistic and comprehensive understanding of the way in which sharinda had to be shot and documented against the backdrop of the geographical features of the land and landscape of origin, with the audio track reproducing to precision the nuances of the sound reinforced by the voice-over of the poetic texts that spoke about both the instrument and the landscape, all in order to stimulate viewing as a live cultural circuit (to borrow and modify Louise Rosenblatt's proposition in Literature as Exploration (1938) that evolves out of this intellectual osmosis.

Several theoreticians, Henry Kreisel and Ashis Nandy being the most prominent, have also spoken about the link between literature and geography, landscape and the human psyche. Henry Kreisel is of the view that all discussion to the literature produced in the Canadian West or the Canadian Prairie $^{7}$ "must of necessity begin with the impact of the landscape upon the mind" (173). What is true of the Canadian Prairie literature is universally true for all literatures (oral and written) across the world (including refugee oral narratives of the lost land mentioned earlier and modern Kokborok poetry) and also for all cultural texts in their all-inclusive textuality including music 
and musical instruments. In the process of shooting and editing it was perceived that instruments such as the sharinda are inextricably intertwined with the landscape and its physical geographical details, often replicating the natural ecological sounds, utilizing ecofriendly materials such as bamboo and wood and reinforcing Ashis Nandy's proposition:

Ours probably is the age of homopsychogeographicus. (Nandy 1999305 ; italics mine.)

This could be extended to the hypothesis that every cultural trace and space including literature and music are ultimately attempts at initiating a cartography of the mind, whose documentation should invariably facilitate an understanding of the homopsychogeographicus of the self. This paper attempts to deal with the inevitable intellectual osmosis that facilitates interaction between geography (in the sense of landscape features) and the human psyche (homopsychogeographicus) to produce cultural products including ethnic musical instruments, literature etal and the way in which they fuse with each other to make a documentary possible. The theoretical frame of the communication model that the documentary mode facilitates in such cases could be diagrammatically represented as follows:

\section{SARINDA - VIDEO DOCUMENTARY MODE:}

(operating at multiple communicational levels)

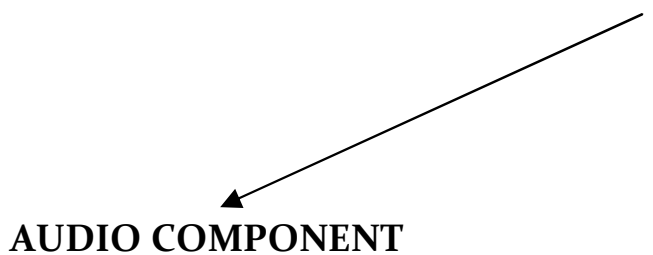

(script- voice recording)

1. Voice Over narration

2. Kokbarak modern poem extracts in Voice Over emphasizing the geographical features of the land.

3. Ambience sounds from environment.

4. Compositions played on the sharinda such as jadu kolija ${ }^{7}$.

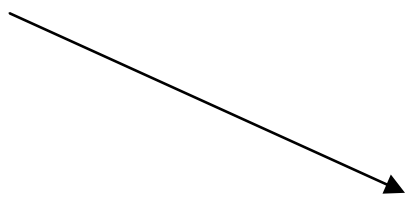

VIDEO COMPONENT

(the script-camera on location)

1. Shots of sharinda.

2. Shots of the land and

landscape.

3. Shots of the musician.

4. Shots of the making process.

On the other hand the research paper format communicates in a linear mode only:

\section{SHARINDA- DOCUMENTATION IN RESEARCH PAPER MODE:}

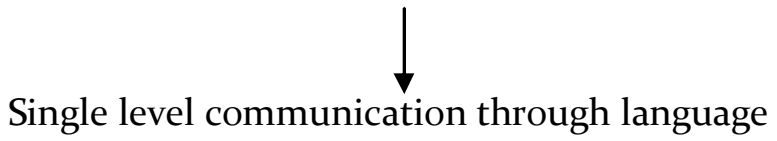

It is interesting to note here that as an integral part of this intellectual osmosis, I also had to negotiate my perspectival prejudices that were the obvious results of my strong emotional attachment to the geography of the land lost during partition and my orientation to other classical and folk, non-ethnic traditions and forms of music that in my psyche created an automatic and immediate comparative paradigm, leading me towards a judgemental position of 
opinionating that was bound to be erroneous- of the sharinda being less musical and melodious and even monotonous. That I belong to the Bengali community and not to the ethnic tribal community of Tripura, have also moulded the perspective of this study considerably leading to this judgement. The resultant triangulation of structure in which all these factors are inextricably and cumulatively interwined and require negotiation can be diagrammatically represented as:
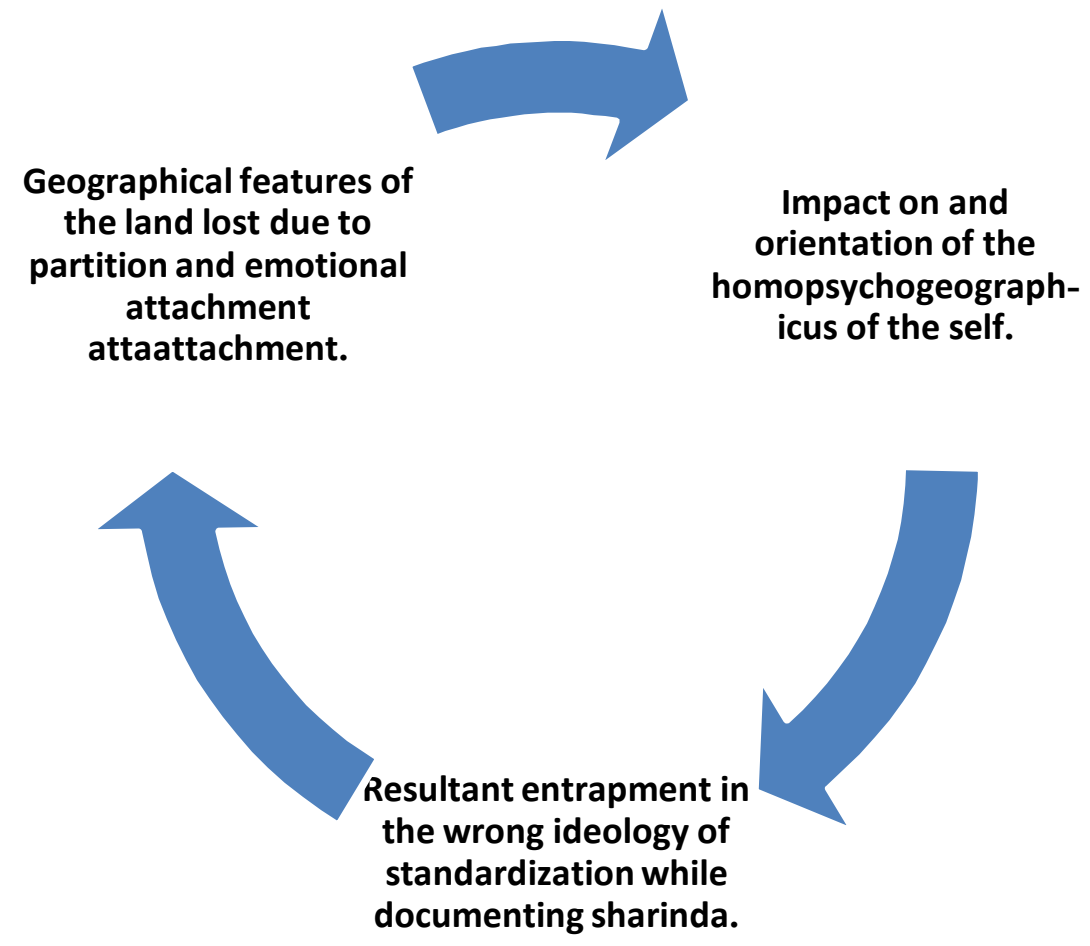

This paper therefore, also attempts at interrogating my very own position and perspective since I can at best claim to be an involved outsider and not an involved insider ( a condition attributive to my emotional attachment to the geography of the land lost and distanciation from the geography of Tripura shaping my homopsychogeographicus). To me and to many others like me who are at best involved outsiders, the music of the sharinda is 'monotonous' as we tend to evaluate it in standards that are extraneous to the culture of origin of the sharinda and is superimposed. The wrong ideology of standardization operating here also tends to locate more 'musicality' in the sarengi for instance by constructing a binary of monotony vs. melody respectively. The task was doubly difficult as on one hand I had to resist being trapped in this wrong ideology of standardization that was so intrinsic to my upbringing in my own culture (the 'self determined by the geography of the land lost) and term the sharinda (belonging to the culture of the 'other') as limited and monotonous and at the sametime initiate a comparison that would be neutral and unbiased to both. My first option was to do so in the voice over (the audio component), but it ran the risk of legitimizing and naturalizing the ideology of standardization referred to. My choice of the documentary mode enabled me to explore the video component without any voice over and only the sound of the sharinda and sarengi in jugalbandi ${ }^{8}$, each speaking for itself but in unison with the sepia colour tone lending a sense of antiquity to both. Thus the video documentary mode not only enabled negotiating this perspectival problem, it also provided a dialectical space for the evolution of a 'live circuit' of communication and 
comprehension to use Louise Rosenblatt's phrase. At the same time this mode also facilitated the expression of my homopsychogeographicus as it responded to the sharinda- sarengi duality and related marginal vs. mainstream as well as monotony vs. melody issues. The making process of the documentary snippet thus was also in some way a delineation of the cartography of my 'self.

It is necessary to mention here that cultural activists like Bikash Ray Debbarma and Nanda Debbarma are putting in their efforts to revive and revitalize the 'music of the soil'- ethnic music forms, melodies and musical instruments to save them from oblivion, the main hurdles towards which, they say, is the lack of grammar, notation and guru-shishya parampara. Ethnic musical instruments like the chongpreng ${ }^{9}$, sharinda and kham ${ }^{10}$ never had a history of royal patronage either and have been alive as a part of oral history and literature as well as folk music and popular culture of the minstrels and the masses who are umbilically connected to the geography of the land. The cultural revivalist efforts do not however end at this, they extend to developing the right critical paradigm and constructing the right perspective towards such ethnic musical instruments as the sharinda so as to counter and resist unjust ideologies of standardization by asserting cultural specificity towards formulation of indigenous aesthetic standards as primary determiners.

The intellectual osmosis referred to demands documentation in the video documentary mode all the more since the sharinda is a cultural product and ambassador metaphorically representing the ethnic way of life and culture threatened to extinction, the elemental simplicity and essential melancholy of its melody being analogous to a simpler life once lived, now sadly lost. Smt. Shefali Debbarma a modern Kokbarak poetess in 'Who shall wake us up?' recounts:

On a bright moonlit evening

playing on his chongpreng,

my grandpa came down the stairs and sat.

The strains of that melody still linger in my heart.

With cobwebs of my grandpa's memory in a corner of the room

hangs the sharinda, its strings ruptured.

I ask myself, "Stringing it again,

who shall evoke the lost tune?

(Shefali Debbarma. The fragrant joom, p.27)

The very process of writing this paper is also in itself an attempt at introspection and self scrutiny, of revaluation of the usual mode of documentation in a research article format and an understanding that the act of writing such a paper typographically tends to limit the varied and myriad possibilities of the subject in question. Hence the choice of the video documentatry mode of documentation where multiple audio tracks through editing and mixing can simultaneously document and disseminate the sound of the chongpreng, English translations of Kokbarak poetry in voice over and other ambience sounds, while the video component could do justice to scenes of Tripura and its geographic details, the ethnic life style and the life writing of the instrumentalist as well as the homopsychogeographicus of the film maker ( here me), inorder to ground the snippet in a geographic and cultural specificity. This paper therefore negates itself by arguing for the inadequacy of typographical documentation since only the making of a documentary snippet on sharinda with all essential dramatizations and stylizations integral to film making could actually account for the fact that this musical instrument provides a dialectical space for intellectual osmosis across disciplinary boundaries of literature, culture and geography. 
60 | The Chitrolekha Journal on Art and Design, Vol. 1, No. 2, 2017

Appendix

Screenshots from the Documentary
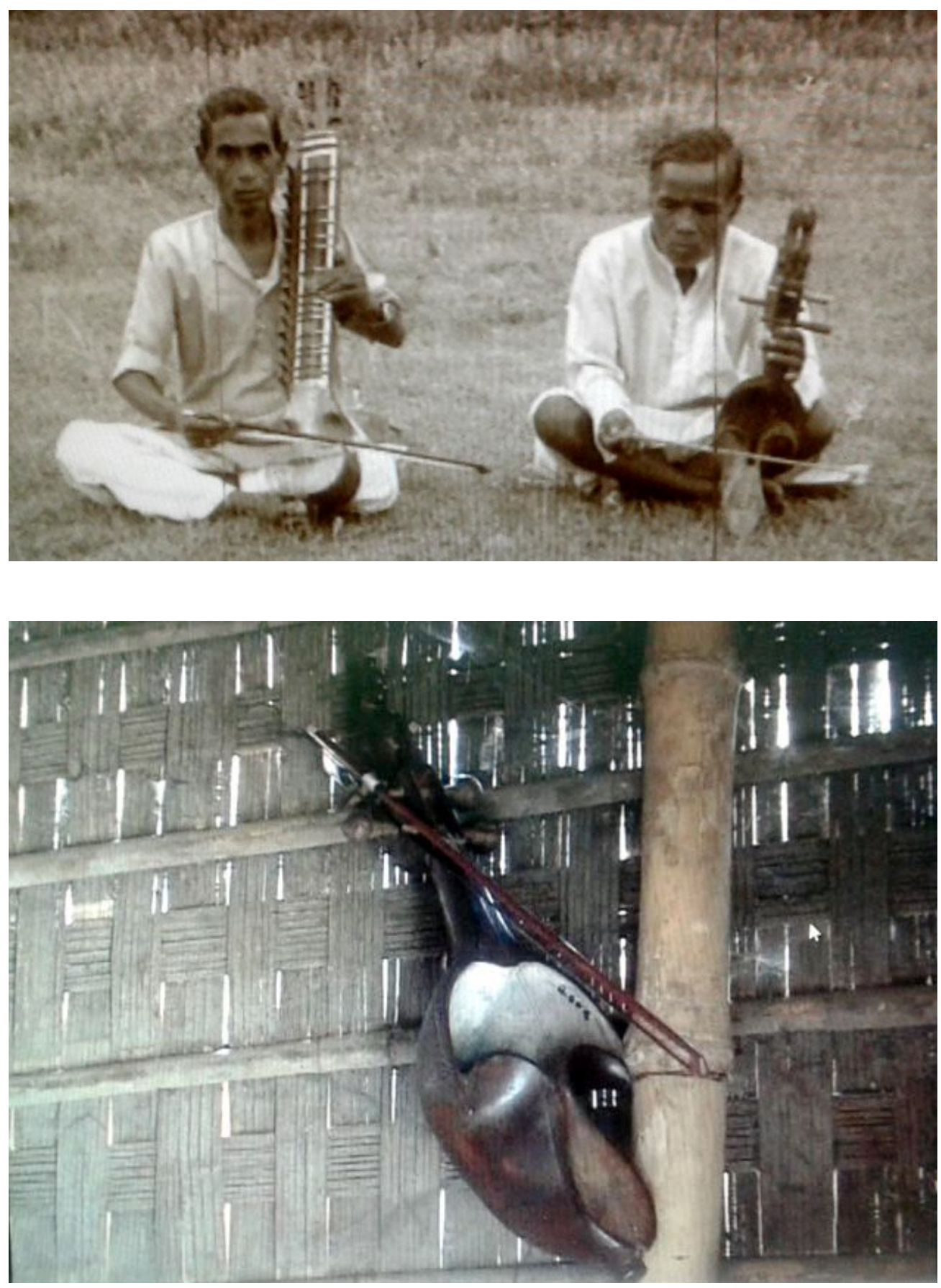

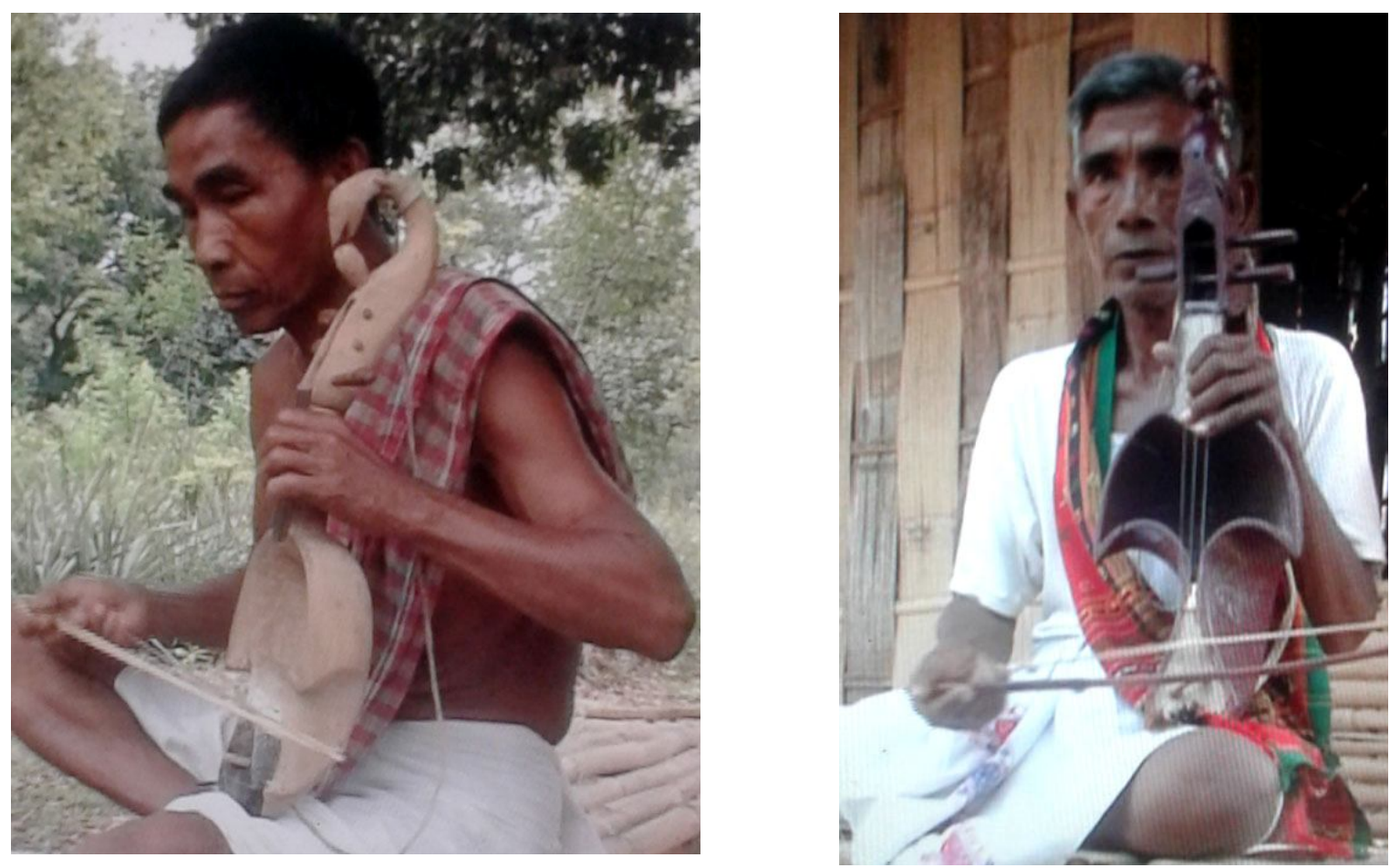

\section{Notes}

1. Loosely means a house and is more structural in connotation.

2. Loosely means 'home' and is connotative of emotion and warmth.

3. Roughly means the geography of the human psyche, used by Nandi to denote the way in which victims of partition respond to the land and landscape lost.

4. A stringed musical instrument played by the tribals of Tripura with close affinities to the 'sarengi'.

5. Another stringed musical instrument of the Hindustani classical musical tradition. The sharinda as well as the sarengi are played with a bow across the strings.

6. A language belonging to the Tibetan Burmese language family and spoken by a majority of tribal population in Tripura.

7. Occupying a little of southern Manitoba, all of southern Saskatchewan and most of southern Alberta are the grasslands, the "true" prairie in Canada.

8. The classical music tradition of pairing two instruments in orchestration.

9. A chordophonic lute played by the tribal communities of Tripura categorized as 'tato' or 'tantu vadya' meaning it is chordophonic. It is a stringed chordophonic lute which has a small range as far as sound and tune are concerned. as a Hindustani classical musical instrument.

10. A percussion instrument or drum of the Reang community primarily.

\section{References}

Debbarma, Bikash Ray. 'Fading Melodies'. Dir. Ashes Gupta. Trinity Films: Agartala: $5^{\text {th }}$ Sept. 2009.

Gupta, Ashes. ed and trans. The Fragrant Joom: A Translation of Kokborok Poetry in English. Agartala: Akshar Publications, 2006. Print.

Iser, Wolfgang. The Act of Reading: A Theory of Response, trans. Iser. Baltimore: John Hopkins Press. 1976. Print. 
- The Implied Reader: Patterns of Communications Prose Fiction from Bunyan to Beckett, trans. Iser.Baltimore:John Hopkins Press.1974. Print.

Malinowski, B.A. Scientific Theory of Culture and Other Essays, Galaxy Books: New York, 196o. Print.

Nandi, Ashis. 1999. 'The invisible holocaust and the journey as an exodus: the poisoned village and the stranger city'. Post Colonial Studies, Vol.2, No.3, p 305-329.

Philips, Dana. The Truth of Ecology. Oxford University Press: New York. 2003. Print.

Rosemblatt, Louise M. Literature as Exploration. 1938. $5^{\text {th }}$ ed. New York: MLA, 1995. Print.

----. 'Reaffirming Literature as Exploration'. Transactions with Literature: A Fifty-Year Perspective: For Louise M. Rosenblatt. Ed. Edmund J. Farell and James R. Squire. Urbana: NCTE, 199o. Print.

Seigneurie Ken. Crisis and Memory: The Representation of Space in Modern Levantine Narrative. Wiesbaden, Germany: Reichert. 2003. Print

Ryle, Gilbert. The Concept of the Mind, Penguin Books Ltd.: New York, 1949. Print.

Born to a family of theatre practioners and painters, Ashes was inherently inspired to think of the world in terms of colour. As he grew up, he took to the brush quite naturally. This passion for colours, both on and off canvas, prompted him to pursue a theoretical formulation of colourusage- colour response application in textual space for his doctoral thesis. His love for the North East of India, his homeland, has been the stimulus behind much of his academic and critical work ranging from situating Mamang Dai's poetry in an authentic NE philosophic and aesthetic paradigm to analyzing the mnemonics of recall foregrounding refugee narratives and comprehending the plebian banter at work in subverting divinity as a remote construct in popular dance performances by the subalterns. As a professor in the department of English, Tripura University, Ashes has been trying to promote NE literature and culture persistently. In his capacity as a documentary film maker on aspects of NE and Tripura, he has created a rich audiovisual archive of lesser known aspects of his homeland. His literary works include Colourscapes: Theorising Colours, The Fragrant Joom, The Golden Rendezvous, Phoenix, The Fragrant Joom: A Translation of Kokborok Poetry in English, The Mystic Mountain: A ranslatio of Tripura Bangla Poetry in English etal. His areas of interest comprises of Indian English Writing, NE Writing, Culture and Aesthetics, Popular Literature and Culture and Film Studies. A few of his documentaries are Vanaaj: In Search of Green, Doibee: An Encounter with the Gods and Fading Melodies: Ethnic Musical Instruments of Tripura. 